www.jmscr.igmpublication.org Impact Factor 5.244

Index Copernicus Value: 83.27 ISSN (e)-2347-176x ISSN (p) 2455-0450 crossref DOI: http://dx.doi.org/10.18535/jmscr/v4i7.11

\title{
Characteristics and Associations of Renal Dysfunction at Presentation in Haart-Naïve HIV-Infected Subjects in Port Harcourt, Nigeria
}

\author{
Authors \\ ${ }^{1}$ OKO-JAJA, Richard I., ${ }^{2}$ AWOPEJU, Abimbola Temitayo O \\ ${ }^{1}$ Dept of Medicine, College of Health Sciences University of Port Harcourt, \\ PMB 5323, Rivers State, Nigeria \\ ${ }^{2}$ Dept of Medical Microbiology and Parasitology, College of Health Sciences University of Port Harcourt, \\ PMB 5323, Rivers State, Nigeria \\ Email: drawopeju@yahoo.co.uk+2348033410038 \\ ${ }^{1}$ Corresponding Author \\ OKO-JAJA, Richard I. \\ Dept of Medicine, College of Health Sciences University of Port Harcourt, PMB 5323, Rivers State, Nigeria \\ Email: rose.rich2011@gmail.com+2347066767449
}

\begin{abstract}
Renal impairment is a major concern for HIV-infected individuals. It affects the way of life of the patients and could lead to a poor prognosis during the course of treatment. A retrospective study of 375 newlydiagnosed HAART naïve HIV-infected individuals from April 2014 to April 2015 was carried out. Information collected from the patients' hospital folders include: Data and reports of biochemical and hematological investigations. Estimated glomerular filtration rate was calculated using the MDRD equation. Patients were grouped according to the WHO clinical stage of HIV disease and the KDIGO CKD stages. The Kruksall-Wallis's and Dunn's posts test was used to compare the difference between the PCV and CD4 cell counts of the different groups. Chi-square analysis of the proportions of subjects according to WHO clinical stage of HIV disease at presentation and CKD Stages was also performed. Renal failure $(e G F R<60 \mathrm{~mL} / \mathrm{min})$ was highly prevalent $(13.7 \%)$ in the study subjects with a high proportion $(90.1 \%$, $n=46 / 51)$ observed in individuals at Stage 3 and Stage 4 of HIV-disease. A decline in the average packed cell volume (PCV) from CKD stage 1 through 5 and HIV clinical stages 1 to 4 was observed, however it was not significant $(p<0.05)$. Hyperfiltration was observed in $2.9 \%(11 / 375)$ of the study subjects, with a majority $(81.8 \%, 9 / 11)$ at HIV clinical stages 3 and 4. The study showed that renal dysfunction is prevalent in HAART nä̈ve HIV-infected individuals at initial diagnosis. Individuals with a CD4 cell count $<300$ cells $/ \mathrm{mm}^{3}$ are at a higher risk for renal dysfunction. Thorough evaluation and identification of at risk individuals is imperative.
\end{abstract}

Key words: Renal Dysfunction, $H I V, C K D, C D 4, P C V$

\section{INTRODUCTION}

HIV infection is a complex hypercatabolic disease, often associated with comorbidities. The earliest reports of kidney disease in HIV infection were published in the 1980s; retrospectively, these subsequently became recognized as HIV- 
associated nephropathy, HIVAN ${ }^{(1)}$. The clinical features of HIVAN were distinctive, with heavy proteinuria and rapid progression to end-stage kidney disease ${ }^{(2,3)}$.

HIVAN in the pre-HAART era was so frequent/prevalent, especially among Black subjects, it overshadowed all other types of HIVassociated chronic kidney disease, that it almost became synonymous with it ${ }^{(1)}$. Following the advent and widespread administration of HAART in the mid-1990s, however, the prevalence and spectrum of kidney disease began to change ${ }^{(1,4)}$. By the turn of the millennium, the clinical course of kidney disease in HIV infection was reportedly more indolent, the risk of developing end-stage disease had reduced by about $40 \%$ to $60 \%$, 1-year survival rate on dialysis therapy had improved from about $25 \%$ to $75 \%$, and kidney transplantation had become a viable option ${ }^{(1,5)}$. Despite these changes, risk factors for kidney disease among HIV-infected persons have remained prevalent, and kidney disease has persisted as an important cause of ill-health and death even among those on HAART ${ }^{(2)}$.

Hence, as persons infected with HIV live longer while receiving HAART, kidney disease has emerged as a significant cause of morbidity and mortality. Kidney disease should be diagnosed in its earliest stages through thorough screening and evaluation of suspected subjects at the earliest contact with the healthcare system following diagnosis of HIV infection. This is necessary as strategies for early detection and intervention of kidney disease potentially hold promise for profound improvements in clinical outcomes, including meaningful reductions in morbidity and mortality.

\section{METHODOLOGY}

\section{Study population}

A retrospective study of 375 newly-diagnosed HIV-infected adults at the University of Port Harcourt Teaching Hospital, Port Harcourt from April 2014 to June 2015 was carried out. All 375 newly-diagnosed

HIV-infected

subjects subsequently commenced anti-retroviral treatment at the hospital. Ethical approval was obtained from the Ethic Board of the Hospital.

\section{Data Collection}

Information collected from the patients' hospital folders included demographic data and reports of biochemical and hematological investigations. The subjects were separated into different groups of clinical stages of HIV disease as described by WHO (6). Estimated glomerular filtration rate was calculated using the MDRD equation as described by Cooper et al (7). The subjects were grouped according to the CKD staging according to the KDIGO guidelines ${ }^{(8)}$.

\section{Data Analysis}

The median and interquartile range of CD4 counts and PCV were calculated and compared with the Kruksall-Wallis test between the groups and the Dunn's posts test was used to compare the difference between two groups. The chi-square test was used to compare the proportions of subjects according to WHO clinical stage of HIV disease at presentation and CKD Stages. All statistical analysis was carried out using the Graphpad prism software; tests were considered significant at $\mathrm{p}$-value of $<0.05$.

\section{RESULTS}

Median age of subjects was 35 (IQR, 29.5 - 42) years. There were $259(69.1 \%)$ female and 116 (30.9\%) male subjects. Amongst the subjects, 180 (48.1\%) were married, 102 (27.2\%) were single, $20(5.3 \%)$ were widowed, 11 (2.9\%) were divorced and $6(1.6 \%)$ were separated $56(14.9 \%)$ did not disclose their marital status. According to the WHO clinical staging of HIV disease, 54.9\% (206/375) of the patients were in Stage 4 of disease presentation. There were $30.9 \%$ (116/375) in Stage 3 of HIV disease, $8.5 \%$ (32/375) were in stage 2, while $5.6 \%(21 / 375)$ were in Stage 1 of HIV disease (Table 1). 
Table 1: Demographic Characteristics of Patients

\begin{tabular}{lll}
\hline Variable & Description & Frequency $(\%)$ \\
\hline Age (median, IQR) & & $35(29.5-42)$ \\
Sex & Male & $116(30.9 \%)$ \\
Marital Status & Female & $259(69.1 \%)$ \\
& Single & $102(27.2 \%)$ \\
& Married & $180(48.1 \%)$ \\
& Divorced & $11(2.9 \%)$ \\
& Separated & $6(1.6 \%)$ \\
& Widowed & $20(5.3 \%)$ \\
WHO Clinical Stage & Undisclosed & $56(14.9 \%)$ \\
& Stage 1 & $21(5.6 \%)$ \\
& Stage 2 & $32(8.5 \%)$ \\
& Stage 3 & $116(30.9 \%)$ \\
& Stage 4 & $206(54.9 \%)$ \\
\hline
\end{tabular}

IQR: Interquartile range

Table 2 shows the median CD4 cell counts and Packed Cell Volume (PCV, \%) of the subjects according to their clinical stages of HIV disease. Median CD4 cell count of $632(563$ - 728) and PCV of 36.0 (34.0 - 39.5) were observed in subjects at Stage 1 of HIV disease. Subjects at Stage 2 had a median CD4 cell count of 364 (213 - 422) and PCV of 33.9 (31.0 - 37.1). The median CD4 cell count and PCV of individuals at Stage 3 of HIV disease were $271(219-308)$ and 32.8
(30.1 - 36.5) respectively, while subjects at Stage 4 of HIV disease had a median CD4 cell count and PCV of $99(48-148)$ and 32.0 (28.4 - 36.0), respectively. There was a significant difference $(\mathrm{p}$ $<0.05$ ) between the median CD4 count of subjects in the different clinical stages of HIV disease, while the difference between the median PCV of subjects at the different clinical stages of disease presentation was not significant $(\mathrm{p}>$ 0.05).

Table 2: Average CD4 and Packed cell volume (PCV) of patients according to WHO clinical stages of Disease Presentation

\begin{tabular}{lll}
\hline WHO Clinical Stage & CD4 (Median, IQR) & PCV \% (Median, IQR) \\
\hline Stage 1 & $632(563-728)^{\mathrm{a}}$ & $36.0(34.0-39.5)^{\mathrm{b}}$ \\
Stage 2 & $364(213-422)^{\mathrm{a}}$ & $33.9(31.0-37.1)^{\mathrm{b}}$ \\
Stage 3 & $271(219-308)^{\mathrm{a}}$ & $32.8(30.1-36.5)^{\mathrm{b}}$ \\
Stage 4 & $99(48-148)^{\mathrm{a}}$ & $32.0(28.4-36.0)^{\mathrm{b}}$ \\
\hline
\end{tabular}

${ }^{\mathrm{a} D i f f e r e n c e ~ i s ~ s t a t i s t i c a l l y ~ s i g n i f i c a n t ~}(\mathrm{p}<0.05)$

${ }^{\mathrm{b}}$ Difference is not statistically significant $(\mathrm{p}>0.05)$.

IQR: Interquartile range PCV: Packed Cell Volume

Median estimated glomerular filtration rate (eGFR) of subjects according to CKD stages are as follows: 106ml/min (Stage 1), $77 \mathrm{ml} / \mathrm{min}$ (Stage 2), $55 \mathrm{ml} / \mathrm{min}$ (Stage 3a), 39.4ml/min (Stage 3b), $22.7 \mathrm{ml} / \mathrm{min}$ (Stage 4), $7.2 \mathrm{ml} / \mathrm{min}$ (Stage 5), while subjects with Hyperfiltration had a median eGFR of $159 \mathrm{ml} / \mathrm{min}$. Median PCV in subjects at CKD Stage 1 and Stage 3a were $30.0 \%$ respectively, those in Stage 2 had a median PCV of $31.0 \%$. A median PCV of $30.6 \%$ was observed in subjects at CKD Stage $3 b$, subjects at CKD Stage 4 had a median PCV of $31.2 \%$, with a median PCV of $32.0 \%$ observed in subjects at CKD stage 5, while median PCV in subjects with Hyperfiltration was $30.1 \%$. Median CD4 cell counts observed include: 175 cells (Stage 1), 183 
cells (Stage 2), 134 cells (Stage 3a), 104 cells (Stage 3b), 54 cells (Stage 4), 160 cells (Stage 5), while a median CD4 cell count of 210 was observed in subjects with Hyperfiltration (Table $3)$.

Table 3. Average eGFR, PCV and CD4 Cell counts according to CKD stages.

\begin{tabular}{llll}
\hline CKD Stage & eGFR $(\mathrm{ml} / \mathrm{min})$ & PCV $(\%)$ & CD4 (cells/ $\mu \mathrm{L})$ \\
\hline Hyperfiltration & 159.0 & 30.1 & 210 \\
Stage 1 & 106.0 & 30.0 & 175 \\
Stage 2 & 77.0 & 31.0 & 183 \\
Stage 3a & 55.6 & 30.0 & 134 \\
Stage 3b & 39.4 & 30.6 & 104 \\
Stage 4 & 22.7 & 31.2 & 54 \\
Stage 5 & 7.2 & 32.0 & 160 \\
\hline eGFR: estimated glomerular filtration rate & & \\
PCV: Packed Cell Volume & &
\end{tabular}

Table 4 shows the frequency of the individuals in the different Chronic Kidney Disease (CKD) stages according to the WHO clinical stages of disease presentation. Of the individuals in Stage 1 of clinical disease presentation, 9 (42.9\%) were in CKD Stage 1, 6 (28.6\%) were in Stage 2, 4 $(19.0 \%)$ were in Stage 3a, and $2(9.5 \%)$ had Hyperfiltration. None of the individuals in Stage 1 of disease presentation were in CKD Stages $3 b, 4$ and 5. Fourteen $(43.8 \%)$ of the individuals at WHO Stage 2 of clinical disease presentation were at CKD Stage 1, 17 (53.1\%) were at Stage 2, only $1(3.1 \%)$ was at Stage $3 a$, while none of them were at CKD Stages 3b, 4, 5 and Hyperfiltration. CKD distribution of individuals at WHO Stage 3 of disease presentation was: Stage $1(n=48$, $41.4 \%)$, Stage $2(n=52,44.8 \%)$, Stage $3 a(n=6$, $5.2 \%)$, Stage $3 b(n=2,1.7 \%)$, Stage $5(n=3$, $2.6 \%$ ), while $5(4.3 \%)$ of the subjects had Hyperfiltration and none was in CKD Stage 4. The CKD distribution of subjects in Clinical Stage 4 of disease presentation include: Stage 1 ( $\mathrm{n}=$ $153,40.8 \%)$, Stage $2(n=160,427 \%)$, Stage $3 a(n$ $=28,7.5 \%)$, Stage $3 b(n=13,3.5 \%)$, Stage $4(n=$ $4,1.1 \%)$, Stage $5(n=6,1.6 \%)$ and $11(2.9 \%)$ had Hyperfiltration.

Table 4. Frequency of Stages of Renal Dysfunction according to WHO Clinical stages of Disease Presentation

\begin{tabular}{|c|c|c|c|c|c|c|c|}
\hline \multirow{2}{*}{ CKD Stages } & \multirow{2}{*}{ eGFR range } & \multicolumn{4}{|c|}{ HIV Clinical Stage, n (\%) } & \multirow{2}{*}{ Total } & \multirow[b]{2}{*}{$\chi^{2}$} \\
\hline & & Stage 1 & Stage 2 & Stage 3 & Stage 4 & & \\
\hline Hyperfiltration & $>150$ & $2(9.5)$ & $0(0.0)$ & $5(4.3)$ & $4(1.9)$ & $11(2.9)$ & $5.4885^{b}$ \\
\hline Stage 2 & $60-89$ & $6(28.6)$ & $17(53.1)$ & $52(44.8)$ & $85(41.3)$ & $160(42.7)$ & $2.0203^{b}$ \\
\hline Stage $3 a$ & $45-59$ & $4(19.0)$ & $1(3.1)$ & $6(5.2)$ & $17(8.3)$ & $28(7.5)$ & $5.5680^{b}$ \\
\hline Stage 4 & $15-29$ & $0(0.0)$ & $0(0.0)$ & $0(0.0)$ & $4(1.9)$ & $4(1.1)$ & $3.2815^{b}$ \\
\hline Stage 5 & $<15$ & $0(0.0)$ & $0(0.0)$ & $3(2.6)$ & $3(1.5)$ & $6(1.6)$ & $1.5797^{b}$ \\
\hline Total & & $21(100)$ & $32(100)$ & $116(100)$ & $206(100)$ & $375(100)$ & \\
\hline
\end{tabular}

$\chi^{2}=$ Chi-square statistics

${ }^{b}$ Difference between the groups are not statistically significant.

eGFR: estimated glomerular filtration rate 


\section{DISCUSSION}

This study showed a greater proportion $(30.9+$ $54.9=85.8 \%$ ) of the HAART- naïve HIV patients had an average CD4 cell count below 300 cells $/ \mathrm{mm}^{3}$. This is in agreement with similar studies in Nigeria which reported a relatively high proportion $(50-85 \%)$ of individuals at WHO clinical Stage 3 and Stage 4 at initial presentation $(9,10)$. This high proportion of relatively low CD4 counts of the individuals at diagnosis may be attributed to the poor health seeking habits experienced especially in developing countries such as Nigeria ${ }^{(11,12)}$.

Overall, difference in average packed cell volume (PCV) observed through CKD 1 to 5 was not significant $(\mathrm{p}>0.05)$. However, this decline in $\mathrm{PCV}$ as the clinical stages of the HIV infection progressed, corresponded with declining renal function $(<60 \mathrm{~mL} / \mathrm{min})$. This is in agreement with Choi et al. ${ }^{(13)}$, which reported corresponding decrease in average PCV as CD4 cell counts decline in a group of HIV infected patients. Anemia has been previously reported to be prevalent among HIV-infected individuals, while the severity of anemia tends to increase as the HIV infection progresses ${ }^{(2,14)}$.

It was observed that $13.7 \%$ of the HIV infected individuals exhibited low renal function $(<$ $60 \mathrm{~mL} / \mathrm{min})$. This is relatively higher than the $3.5 \%-9.7 \%$ proportion of individuals with diminished renal function as reported in Asian and European HIV-infected populations (2, 15, 16). However, this finding was consistent with the findings of Lucas et al., which reported a 6-fold GFR decrease in HIV- infected blacks, compared to HIV-infected whites ${ }^{(17)}$. It has also been previously reported, that about $91 \%$ of HIVinfected persons receiving dialysis in the United States were blacks ${ }^{(1,15)}$. Individuals of African descent have been considered to have a higher risk of HIV-associated nephropathy due to their peculiar predilection to podocyte proliferation and tubular dilatation with atrophy and flattening of the tubular cells ${ }^{(15-17)}$. In the pre-HAART era, HIVAN with its dramatic clinical features, was so frequent that it became almost synonymous with HIV-associated chronic kidney disease especially in black person between $20-64$ years of age ${ }^{(2,18)}$. In this study, 90.2\% (46/51) of the individuals with renal dysfunction (eGFR $<60 \mathrm{~mL} / \mathrm{min}$ ) was found in HIV clinical stages 3 and 4. Ando and Yanagisawa, have stated that low CD4 cell count was a risk factor for associated chronic kidney disease ${ }^{(3)}$. This could also be attributed to the accelerated aging due to persistent viral replication and chronic systemic inflammation in HIV-infected individuals ${ }^{(19)}$. Commonly-abused, readily-available antipyretic and analgesics agents such as NSAIDS, could lead to nephrotoxicity causing renal failure.

Hyperfiltration (eGFR $\geq 150 \mathrm{~mL} / \mathrm{min})$ was observed in $2.9 \%(11 / 375)$ of the study subjects, with $81.8 \%(9 / 11)$ of the subjects in HIV clinical stages 3 and 4 . This is consistent with the report of $\mathrm{Ng}$ et al., which showed that HIV infection is associated with higher odds of hyperfiltration ${ }^{(20)}$. Hyperfiltration is an important marker for future renal dysfunction and end-stage kidney disease ${ }^{(2,}$ 20). This phenomenon may also be due to direct viral injury to the kidney, accelerated organ aging or individual dietary habits ${ }^{(19)}$. Direct viral infection of renal epithelial cells disturbs podocyte structure and function with subsequent upregulation of renin-angiotensin system which is held to central to the pathophysiology of hyperfiltration ${ }^{(20-22)}$.

\section{CONCLUSION}

The study showed that renal dysfunction was prevalent in HIV-infected persons at first presentation and diagnosis. Majority of these subjects were at HIV clinical stages 3 and 4 . Anemia was mild across all stages of HIV-disease and CKD stage. Thorough clinical examination and evaluation for CKD should be conducted, especially at the earliest contact with health care system. Early detection of chronic kidney disease (CKD) is imperative to identify those most at risk of further deterioration of renal function, and 
institution of optimal care. A multi-center study of this phenomenon is recommended.

\section{REFERENCES}

1. Winston J, Deray G, Hawkins T, Szczech L, Wyatt C, Young B. Kidney disease in patients with HIV infection and AIDS. Clinical Infectious Diseases, 2008; 47: 1449 - 14457.

2. Palatini P. Glomerular Hyperfiltration: A marker of early renal damage in prediabetes and pre-hypertension. Nephrology Dialysis Transplantation, 2012; 0: 1 - 7.

3. Ando M, Yanagisawa N. Epidemiology, clinical characteristics, and management of chronic kidney disease in human immunodeficiency virus-infected patients. World journal of nephrology, 2015; 4(3): $388-395$.

4. Schwatz EJ, Szczech LA, Ross MJ, Klotman ME, Winston JA, Klotman PE. Highly-active antiretroviral therapy and epidemic of HIV + end-stage renal disease. Journal of American Society of Nephrology, 2005; 16: 2412 - 2420.

5. Lucas GM, Ross MJ, Stock PG, Slipak MG, Wyatt CM, Gupta SK et al., Clinical Practice guideline for the management of chronic kidney disease in patients infected with HIV: 2014 update by the HIV Medicine Association of the Infectious Diseases Society of America. Clinical Infectious Diseases, 2014; 59: 96 - 138.

6. World Health Organization. WHO Case Definitions of HIV for Surveillance and Revised Clinical Staging and Immunological Classification of HIVRelated Disease in Adults and Children. http://www.who.int (2007). Accessed 20 th December, 2015.

7. Cooper RD, Natasha W, Smith N, Philip K, Saraladevi N, Marcello T. Systematic Review and Meta-analysis: Renal Safety of TenofovirDisoproxilFumarate in HIV-
Infected Patients. ClinInfec Dis. 2010; 51:496-505.

8. Levey AS, de Jong PE, Coresh J, El Nahas M, Astor BC, Matsusshita K. The definition, classification and prognosis of chronic kidney disease: a KDIGO Controversies conference report, Kidney International, 2011; 80: 17 - 28.

9. Venkat N, Paolo G, Miotti NP, Anand JD, Kline LM, Harmston C, et al HIV and Noncommunicable Disease Comorbidities in the Era of Antiretroviral Therapy: A Vital Agenda for Research in Low- and Middle-Income Country Settings. J Acquir Immune DeficSyndr 2014; 67:S2 - S7

10. Adebayo SB, Olukolade RI, Idogho O, Anyanti J, Ankomah A. Marital Status and HIV Prevalence in Nigeria: Implications for Effective Prevention Programmes for Women. Advances in Infectious Diseases, 2013 3: 210-218.

11. Katz IT, Ryu AE, Onuegbu AG, Psaros C, Weiser SD, Bansberg DR, et al. "Impact of HIV-related stigma on treatment adherence: systematic review and meta synthesis," J Int AIDS Soc, 2013; 16 (2), 18640 - 18664

12. Joseph L. Kamalika M, Madhu V, Neeraj $\mathrm{KC}$, Sanjay M. Late presenters to HIV care and treatment, identification of associated risk factors in HIV-1 infected Indian population. BMC Pub Health2010, 10:416

13. Choi AI, Li Y, Deeks SG, Grunfeld C, Volberding PA, Shlipak MG. Association between kidney function and albuminuria with cardiovascular events in HIV-infected persons. Circulation, 2010; 121: $651-658$.

14. Peralta CA, Shlipak MG, Judd S, Cushman M, McClellan W, Zakai NA. Detection of Chronic Kidney Disease with creatinine, cystatin $\mathrm{C}$, and urine albuminto-creatinine ratio and association with progression to end stage renal disease and mortality. JAMA, 2011; 305: 1545 - 1552. 
15. Ryom L, Kirk O, Lundgren JD, Reiss P, Pedersen C, De Wit S, Buzunova S. Advanced chronic kidney disease, endstage renal disease and renal health death among HIV-positive individuals in Europe. HIV Medicine, 2013;14: 503-508.

16. Yanagisawa N, Ando M, Ajisawa A, Imamura A, Suganama A. Clinical Characteristics of kidney disease in Japanese HIV-infected patients. Nephrology Clinical practice, 2011; 118: $285-291$.

17. Lucas GM, Lau B, Atta MG, Fine DM, Keruly J, Moore RD. Chronic kidney disease incidence and progression to endstage renal disaes in HIV-infected individuals: a tale of two races, Journal of infectious diseases, 2008; 197: 1548 1557.

18. US Renal Data system. USRDS 2007 Annual data report: atlas of chronic kidney disease and end-stage renal disease in the United States. Bethesda, MD: National Institutes of Health, National Institute of Diabetes and Digestive and Kidney Diseases, 2007.

19. Deeks SG. HIV infection, inflammation, immunosenescence, and aging. Annual Review of Medicine 2011; 62:141-55.

20. Ng DK, Jacobson LP, Brown TT, Palella FJ, Martinson JJ, Bolan R.HIV therapy, metabolic and cardiovascular health are associated with glomerular hyperfiltration in the Multicenter AIDS Cohort Study. AIDS. 2014 January 28; 28(3): 377-386.

21. Lu T-C, He JC, Klotman PE. Podocytes in HIV-associated nephropathy. Nephron ClinPract. 2007; 106: c67-71. [PubMed: 17570932]

22. Chandel N, Sharma B, Husain M, Salhan D, Singh T, Rai P, et al. HIV Compromises Integrity of Podocyte Actin Cytoskeleton through down regulation of Vitamin D receptor. Am J Physiol Renal
Physiol Published Online First. Mar 6.2013 doi:10.1152/ajprenal.00717.2012. 